\title{
Reform and Exploration on Mixed Computer Education Mode Based on Computational Thinking
}

\author{
Xinfeng Yang ${ }^{\mathrm{a}}$ and Lingxiao Zhang ${ }^{\mathrm{b}}$ \\ School of Computer and Information Engineering, Nanyang Institute of Technology, Nanyang, \\ China \\ a1832370485@qq.com, bnitzlx@163.com
}

Keywords: University computer courses; Computational thinking; Mixed teaching mode

\begin{abstract}
According to the characteristics of students, combined with the characteristics of professional disciplines, the reform of the curriculum content of the university computer courses based on computational thinking training as the teaching goal, the construction of the content system of university computer courses based on subject integration, the construction of multidisciplinary Integration of case base, with MOOC to carry out the "flip classroom" and "mixed teaching" practice, reform the traditional classroom teaching mode, improve the university computer courses and teaching effectiveness.
\end{abstract}

\section{Introduction}

With the development of computer science and technology, information technology has been integrated into all aspects of society. Computational thinking is ubiquitous and has become one of the basic abilities of people to recognize and solve problems. The Teaching Steering Committee of Computer Courses at Higher Education Institutes of the Ministry of Education vigorously promoted the reform of computer courses centered on computational thinking. Under the leadership of the Higher Education Department, a number of teaching reform programs were organized and implemented, and teaching practices were implemented in different types of colleges and universities. A rich course of implementation program was formatted. To sum up, the reform of university computer courses based on computational thinking is imperative. The biggest challenge in the process of reform is how to set up teaching contents and how to select teaching cases under the condition of limited teaching hours, what kind of teaching methods to take to show the basic calculation ideas and methods.

\section{Related Concepts}

\section{Computational Thinking}

According to Prof. Zhou Yizhen, computational thinking is a series of thinking activities that cover the breadth of computer science, such as problem solving, system design and understanding of human behavior, using the basic concepts of computer science. Careful analysis can be found, Professor Zhou Yizhen definition contains three levels of content:

Computational Thinking Consciousness. Computational thinking is a kind of scientific thinking, together with theoretical thinking and experimental thinking, constitute the three major human thinking. Computational thinking is not a new invention, but a pre-existing thinking activity, a skill that everyone has.

In computer course teaching, cases of computational thinking also exist everywhere. The problem is that people's computational thinking activities are unconscious. The key point is to turn the unconscious computational thinking into conscious computational thinking, take the initiative to solve the problem with computational thinking, and apply it in their respective professions.

Computational Thinking Method. Computational thinking method is the core of computational thinking. There are two main types of computer thinking methods: one is from mathematics and engineering and the other is computer science. In college computer courses, almost every concept corresponds to a computational thinking method. For example, Cache is a pre-set and cache method, 
and multicore processors are parallel external methods. In programming courses, various commonly used algorithms and methods for solving various problems, such as iterative methods and recursive methods, are not controversial Computational thinking method; in computer application course, each course of each course is a collection of a variety of computational thinking methods.

Computational Thinking Ability. The fundamental purpose of computational thinking is to solve problems, namely problem solving, system design and understanding of human behavior. From a computer application point of view, to solve the problem is the computer application. For example, designing a database application, creating an e-commerce website, and building a robot are all computer application questions that are the purpose of computational thinking.

The content of computational thinking is not what a course can afford. Computational thinking teaching needs to run through all university computer courses. In the teaching of computer courses in universities, training of computational thinking skills requires a series of computer application courses to support and expand, such as data technology and applications, multimedia technology and application courses. These courses lead students to apply computational thinking to solve a variety of professional issues.

\section{Massive Open Online Courses}

MOOC (Massive Open Online Courses) is an open online course that has emerged in recent years. It has powerful data storage and processing capabilities and can save the learning process, progress and participation in discussions, Through the processing and analysis of big data, real-time understanding of students learning and teaching process of electronic management, but MOOC also has drawbacks, such as the high withdrawal rate, teachers cannot control the process of student learning, exercises and even The exam cannot be guaranteed if the student himself completed. How to make full use of MOOC high-quality shared resources and effectively combine them with classroom teaching so as to promote and integrate each other is the key issue to be solved urgently.

\section{Small Private Online Course}

SPOC (Small Private Online Course) is a branch of MOOC, the scale is generally dozens of people to hundreds of people. MOOC $+\mathrm{SPOC}$ are a proprietary, feature-based open online course for schools based on the same MOOC curriculum. SPOC is divided into synchronous SPOC and asynchronous SPOC, synchronous SPOC means SPOC and MOOC at the same time, students can not only get MOOC team online counseling, and can apply for a certificate of completion; and asynchronous SPOC is released by the school teachers MOOC resources independently, according to the school positioning, Majors and basic differences in enrollment, teachers can add or delete MOOC resources such as short videos, courseware, test questions, final exams and discussion topics, construct higher or lower MOOC benchmark courses, SPOC course resources.

\section{Based on MOOC + SPOC Online and Offline Mixed Teaching Mode}

Based on the MOOC + SPOC online-offline mixed teaching mode, teachers (such as our school or MOOC teachers) provide instructional resources such as teaching videos, topic discussions and test questions on line with the support of modern information technology, online learning by students, Teachers according to online data feedback to determine the contents of the offline classroom, online learning and classroom integration. Flip classroom teaching mode refers to the traditional classroom teaching and learning turned into online teaching and learning, offline discussion and Q \& A mainly to improve student interest in learning and learning.

\section{The Specific Content and Goal of the Reform}

According to the characteristics of students, combined with the characteristics of professional disciplines, the reform of the content of the course of computer courses based on computational thinking to cultivate students as a teaching goal, the construction of a university computer course content system based on subject integration, the construction of computational thinking as the core application Multidisciplinary fusion case base.

Research and Practice a New Hybrid Teaching Model Based on "MOOC + SPOC + Flip Classroom". The model includes four aspects, namely, to create SPOC, students learn before class, 
teachers and students to carry out classroom activities, teachers summed up teaching experience after class.

Create SPOC. Based on the MOOC platform provided by China Computer Education MOOC Alliance, we will construct a SPOC that meets the actual conditions of our university. According to the needs of the course teaching, students should be provided with enough learning resources, including micro-video, exercise books and materials, etc., and an online learning platform should be set up for students to learn and interact with each other before class. Teachers organize small-scale student groups (for example, by class) and set up pre-class guidance for them so that students can take pre-class study with questions.

Learning Before Class. According to the teacher designated learning tasks and guide the problem, the students complete the learning content by watching the micro-video before class during the viewing process, the student's autonomy can be reflected, the video content can be adjusted, the simple can be quickly passed, and the complicated can be viewed repeatedly . Watch and take note of their harvest or doubt, in order to share and share with others. After reading the video to complete the teacher arranged exercises, consolidate the learning content. Through the network communication platform, students and students, students and teachers can interact and solve difficult problems.

Classroom Activities. The main task of classroom activities is to help students to complete the internalization of knowledge, which can be done by organizing students to explore issues, learn collaboratively and interact with each other. The problems of classroom inquiry come from two aspects: (i) the questions that teachers put forward according to the key and difficult points of teaching contents; (ii) the difficult problems that students find according to the pre-class learning situation. Choose some moderate difficulty for students to solve independently, can improve students' ability to think independently and solve problems. Difficult problems can be collaborative group learning, teachers grouped according to student situations and assign tasks. Each member of the group should take an active part in the exploration of the issue; communicate with each other and work together to accomplish the learning task. Students should report and communicate their learning achievements in the classroom so as to achieve the goal of common improvement. Finally, to evaluate the learning process and learning outcomes, the evaluators can be teachers and classmates.

Consolidation After-School. Based on the problems presented in the classroom activities, teachers summarize and optimize the contents, methods, and methods in the teaching process to further improve the teaching mode, improve teaching effectiveness and promote the development of teachers.

\section{The Implementation Plan and Method}

Match with the MOOC alliance's excellent teaching resources to further study the mixed teaching mode of "MOOC + SPOC + Flip Class".

Take calculation thinking as the orientation, tailor and combine important knowledge points of "Computer Introduction" and "Programming Basis", organize the teaching contents of modularization, multi-level and professional integration, formulate the teaching implementation plan based on mixed teaching mode.

Based on the basic and professional features of our students and making full use of the excellent teaching resources of docking in the introduction of "Computer Introduction" and "Programming Basics" for 2017 students majoring in computer science and technology, "MOOC + SPOC + Flip Classroom" Mixed teaching model to carry out the "computer introduction" and "programming foundation" course teaching.

To summarize the teaching process of the course, based on the process implementation and the feedback from the teachers and students, further optimize the teaching content, improve the teaching mode of the course, develop the teaching case and build the teaching system, on the basis of absorbing existing high-quality teaching resources, we set up an open teaching resource platform that meets the actual conditions of our university. 
The project achievements are applied to the "Computer Introduction" and "Programming Basics" teaching of 2018 computer science and technology students, and further optimized.

\section{Summary}

To sum up, the teaching reform of computer courses based on computational thinking in universities is imperative. Based on this, it is necessary for the characteristics of students to combine with the characteristics of specialized disciplines to carry out the curriculum content of computational thinking training for college computer courses Reform and construct a content system of university computer courses based on the integration of disciplines and construct a multidisciplinary integration case library with computational thinking as its core application. In addition, the rise of MOOC is an important turning point for college teaching reform, which not only plays an obvious role in promoting high-level classroom construction in universities, but also plays an important role in promoting the development and sharing of quality education resources. On the one hand, we can use MOOC to carry out the "flip classroom" and "mixed teaching" practice, reform the traditional classroom teaching mode, improve the influence and teaching effect of university computer courses; on the other hand, we can also use the MOOC platform to open a high level, Embodying the course of reform, and improving the teaching level of teachers in teaching, making it an effective way to benefit college students and social learners.

\section{Acknowledgement}

The author is grateful to the support of 2017 Nanyang Institute of Technology Education and Teaching Reform Research Project (NIT2017JY-136).

\section{References}

[1] P.Z. Gong, Z.Q. Yang. China University Teaching, (2012) No.5, p.51.

[2] Y. Zhu, H.W. Yang, X.Q. Song. Computer Education, (2013) No.5, p.35.

[3] H.Q. Tang. Computer Education, (2012) No.21, p.45.

[4] M. He, W.W. Chen, X.L. Chen, X.G. Ye, F. Yang, K. Wang. Computer Engineering \& Science. Vol. 36 (2014) No.A1, p.96.

[5] Y.W. Pu, Z.L. Geng, R. Chen, T. Li. Computer Education, (2013) No.11, p.13.

[6] C.Y. Zhang, Y.Liu, Y.J. Zhao. Cyberizing \& Digitizing, (2016) No.3, p.63.

[7] F.X. Li, Y.F. Chen, Y. Yu. Computer Education, (2016) No.1, p.17.

[8] M.X. Zeng, G.P. Li, Q.P. Zhou. Modern Distance Education Research, (2016) No.1, p.41.

[9] X.H. Su, L.L. Zhao, L. Ye. China University Teaching, (2015) No.7, p.60.

[10]R. Chen, C. Yang. Distance Education in China, (2015) No.5, p.42. 